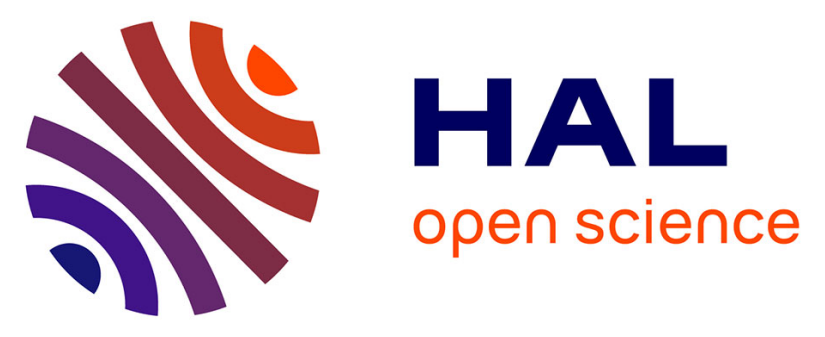

\title{
Kinetic modeling of light limitation and sulfur deprivation effects in the induction of hydrogen production with Chlamydomonas reinhardtii : Part I. Model development and parameter identification
} Swanny Fouchard, Jeremy Pruvost, Benoit Degrenne, Mariana Titica, Jack Legrand

\section{To cite this version:}

Swanny Fouchard, Jeremy Pruvost, Benoit Degrenne, Mariana Titica, Jack Legrand. Kinetic modeling of light limitation and sulfur deprivation effects in the induction of hydrogen production with Chlamydomonas reinhardtii : Part I. Model development and parameter identification. Biotechnology and Bioengineering, 2009, 102 (1), pp.232-245. 10.1002/bit.22034 . hal-01940666

\author{
HAL Id: hal-01940666 \\ https://hal.science/hal-01940666
}

Submitted on 24 Apr 2020

HAL is a multi-disciplinary open access archive for the deposit and dissemination of scientific research documents, whether they are published or not. The documents may come from teaching and research institutions in France or abroad, or from public or private research centers.
L'archive ouverte pluridisciplinaire HAL, est destinée au dépôt et à la diffusion de documents scientifiques de niveau recherche, publiés ou non, émanant des établissements d'enseignement et de recherche français ou étrangers, des laboratoires publics ou privés. 


\title{
Kinetic Modeling of Light Limitation and Sulfur Deprivation Effects in the Induction of Hydrogen Production With Chlamydomonas reinhardtii: Part I. Model Development and Parameter Identification
}

\author{
Swanny Fouchard, Jérémy Pruvost, Benoit Degrenne, Mariana Titica, Jack Legrand \\ GEPEA, Université de Nantes, CNRS, UMR 6144, Bd de l'Université, CRTT - BP 406, \\ 44602 Saint-Nazaire Cedex, France; telephone: 33-2-40-17-26-68; \\ fax: 33-2-40-17-26-18; e-mail: jeremy.pruvost@univ-nantes.fr
}

ABSTRACT: Chlamydomonas reinhardtii is a green microalga capable of turning its metabolism towards $\mathrm{H}_{2}$ production under specific conditions. However this $\mathrm{H}_{2}$ production, narrowly linked to the photosynthetic process, results from complex metabolic reactions highly dependent on the environmental conditions of the cells. A kinetic model has been developed to relate culture evolution from standard photosynthetic growth to $\mathrm{H}_{2}$ producing cells. It represents transition in sulfur-deprived conditions, known to lead to $\mathrm{H}_{2}$ production in Chlamydomonas reinhardtii, and the two main processes then induced which are an over-accumulation of intracellular starch and a progressive reduction of PSII activity for anoxia achievement. Because these phenomena are directly linked to the photosynthetic growth, two kinetic models were associated, the first (one) introducing light dependency (Haldane type model associated to a radiative light transfer model), the second (one) making growth a function of available sulfur amount under extracellular and intracellular forms (Droop formulation). The model parameters identification was realized from experimental data obtained with especially designed experiments and a sensitivity analysis of the model to its parameters was also conducted. Model behavior was finally studied showing interdependency between light transfer conditions, photosynthetic growth, sulfate uptake, photosynthetic activity and $\mathrm{O}_{2}$ release, during transition from oxygenic growth to anoxic $\mathrm{H}_{2}$ production conditions.
Correspondence to: J. Pruvost

Contract grant sponsor: Interdisciplinary CNRS Energy Program (2002-2005) Contract grant sponsor: CPER-Etat-Region of Pays de la Loire (France) Contract grant sponsor: "PhotobioH2" ANR Program (French National Program, 2006-2009)
KEYWORDS: kinetic model; photosynthetic growth; light limitation; sulfur deprivation; hydrogen production; Chlamydomonas reinhardtii

\section{Introduction}

The green microalga Chlamydomonas reinhardtii is known to produce molecular hydrogen in continuous illumination and anoxic conditions. This biological production is linked to the photosynthetic process: microorganisms use light energy to convert water (direct biophotolysis) or endogenous compounds (indirect biophotolysis) to hydrogen (Akkerman et al., 2003; Asada and Miyake, 1999; Das and Veziroglu, 2001). In Chlamydomonas reinhardtii, hydrogen production is catalyzed by an [FeFe]-hydrogenase, with strong enzymatic activity, which interacts with some of the electron carriers involved in the photosynthetic chain to reduce protons in molecular hydrogen. A major limitation is the strong inhibition of hydrogenase by oxygen (Benemann et al., 1973; Ghirardi et al., 1997, 2000). As soon as oxygen is released during water photolysis by photosynthesis, hydrogen release stops. Because light supply is also requested to sustain hydrogen production, overcoming this limitation is difficult to achieve. Due to the incompatibility between photosynthetic growth and hydrogen production conditions, they have to be spatially or temporally separated. A specific protocol, first proposed by Melis et al. (2000), is known to induce in a rather simple manner a time separation between periods of oxygen and hydrogen gas release. After placing cells in a sulfur-deprived medium, anoxia is progressively induced, leading to hydrogen release. 
Although some aspects are still unclear, especially on metabolic pathways reorganization when sulfur deprivation conditions are applied, main features have been widely described in the literature. The most important is a progressive and reversible reduction of the photosynthetic capacities due to the PSII (Photosystem II) inactivation (Antal et al., 2003; Wykoff et al., 1998). This leads to a decline in oxygen release activity and a decrease in the photosynthetic electron flux, while the mitochondrial respiration is maintained. From the imbalance between these two processes results a progressive and reversible reduction of the oxygen concentration in the medium (Wykoff et al., 1998) leading to anoxia. Hydrogenase is then induced and hydrogen released. Remaining PSII activity, although greatly reduced, supplies electrons in transport chain up to the hydrogenase enzyme. It is also known that hydrogen production in sulfur deprivation conditions is the result of two different electrons transfer pathways. The residual photosynthesis (or PSII-dependent pathway, resulting from water photolysis) which should be the principal donors of electrons to the hydrogenase (Antal et al., 2003; Ghirardi et al., 2000) is acting simultaneously with a PSII-independent pathway that uses catabolism of endogenous starch reserves as an additional source of electrons (Fouchard et al., 2005; Posewitz et al., 2004). Indeed, it has been shown that sulfur deprivation also induces an important intracellular starch accumulation. This secondary effect occurs during the first days of deprivation, when PSII activity is still rather unaffected and sufficient to photosynthetically synthesized starch by assimilation of the carbonaceous substrate contained in the culture medium. Under sulfur deprivation conditions, contribution of this PSII-independent pathway is estimated to represent $20 \%$ of total $\mathrm{H}_{2}$ production (Fouchard et al., 2005).

The previously described responses result in a dynamic behavior of the culture with a progressive transition between various physiological states, leading finally to hydrogen release. The culture handling is thus very complex, with strong interactions between several physiological responses. This increases the interest of a dynamic model, linking together main representative responses of the biological system, their respective kinetics, their influence on cells surroundings (especially dissolved oxygen concentration), and how they are influenced by operating parameters. Such kind of model represents a basis for the elaboration of new optimization and control strategies for $\mathrm{H}_{2}$ production in photobioreactor. This is the aim of this study, focused on transient phases preceding $\mathrm{H}_{2}$ production.

To the authors' knowledge, only one model on $\mathrm{H}_{2}$ production by algae placed under sulfur free-conditions was proposed in the literature (Park and Moon, 2007). The $\mathrm{H}_{2}$ producing phase is modeled, providing a detailed biochemical model based on eight primary metabolites. The drawback is that it results in an important number of parameters difficult to identify from available experimental data. In addition, the discrete events introduced in the model (multi-state model) are not suitable to represent the progressive transition from growth to $\mathrm{H}_{2}$ production conditions. Thus, the model developed in the present work differs in structure, even though devoted to the same application. First of all, it will introduce a continuous formulation, so as to represent previously described imbalances between different constitutive phenomena of the progressive transition from oxygenic growth to anoxia. Secondly, attention will be paid to obtain a general model formulation, rather independent of the case under study, with corresponding parameters estimated from individual sets of experiments. This latter condition is indeed important regarding model purpose, which is to optimize culture conditions and investigate new protocols inducing $\mathrm{H}_{2}$ production.

Only successive phases leading to hydrogen production were considered, any formulation of hydrogen release being voluntarily excluded in this study. The main reason is because of the current lack of knowledge on the characterization of hydrogen production pathways. As described previously, hydrogen production is the result of two different pathways, certainly interacting at intracellular level. Without further insight in metabolic mechanisms involved in the hydrogen production phase, it seems unrealistic to propose now a valid representative model dedicated to this phase.

Modeling was conducted on main aspects driving the process towards $\mathrm{H}_{2}$ production conditions. The first major phenomenon to model is the central process of photosynthesis. Numerous works were performed on photosynthetic growth modeling (Cornet et al., 1992; Csögör et al., 1999; Franco-Lara et al., 2006). This is well-known that a strong dynamic coupling exists between light conditions and resulting growth. Accurate formulation of such a coupling is a problem on its own. As soon as light absorption by cells occurs, light transfer inside the culture has to be modeled to correctly consider its influence on the process. If neglected, effects of change in biomass concentration on light attenuation conditions, thereby resulting in photosynthetic growth rates, cannot be accurately represented. The framework of the model will be based on a kinetic formulation of the coupling between light transfer and photosynthetic growth (as usually applied in photobioreactor modeling). This will enable to describe biomass increase during the first phase of the photosynthetic growth, as well as starch accumulation when sulfur starvation occurs. Photosynthetic growth will also be formulated as a function of the amount of sulfur accumulated in cells. This will be achieved by incorporating an intracellular quota formulation, based on Droop (1968) model. Such latter model is classically used in oceanographic studies (Bernard et al., 2007) to consider relation of microalgal growth to the nutrient availability. In the case of light-limited growth culture in photobioreactor, this formulation has to be associated with radiative transfer conditions, introducing the coupling between a radiative model (Pottier et al., 2005) and a Haldane one to represent light-dependent photosynthetic growth kinetics (Andrews, 
1968). It must be noticed that, because of the specific effect of sulfur on PSII and therefore on photosynthetic activity decrease, it was necessary to modify the usual formulation of the growth rate dependence on intracellular sulfur quota, as proposed in the classical Droop model. This was justified by a specific experimental investigation presented in this work where the growth rate was measured as a function of intracellular sulfur quota.

The article is organized as follows: after a material and methods section, key features of the model are described and discussed before the model is presented. A special section is devoted to the model parameter identification from experimental data obtained with especially designed experiments. Finally, the sensitivity of the model to its various parameters is reported. Model validation and its relevance to investigate new protocols leading to the $\mathrm{H}_{2}$ production will be addressed in another article (Part II).

\section{Materials and Methods}

\section{Culture Conditions and Photobioreactor System}

For Erlenmeyers experiments, Chlamydomonas reinhardtii cells (wt 137c strain from the Chlamydomonas Genetic Center, Duke University, Durham, USA) have been placed in photosynthetic growth conditions: $25^{\circ} \mathrm{C}$ in a Tris-acetatephosphate (TAP) medium ( $\mathrm{pH} 7.2$ ), under continuous illumination $\left(245 \mu \mathrm{mol}\right.$ photon $\left.\mathrm{m}^{-2} \mathrm{~s}^{-1}\right)$ and constant stirring.

For experiments conducted in the torus photobioreactor, the $\mathrm{pH}$ (7.3) was regulated by $\mathrm{CO}_{2}$ injection and temperature $\left(25^{\circ} \mathrm{C}\right)$ by ambient air blowing. The photobioreactor system (Fig. 1) is based on an original and fully characterized geometry (torus-shaped photobioreactor) especially adapted for photosynthetic microorganisms cultivation and hydrogen production. A complete description of this reactor can be found in the literature (Fouchard et al., in press; Pottier et al., 2005; Pruvost et al., 2006). For photobioreactor experiments, a minimum medium (MMG) enriched with $20 \mathrm{mM}$ of $\mathrm{NaHCO}_{3}$ was used. MMG has the

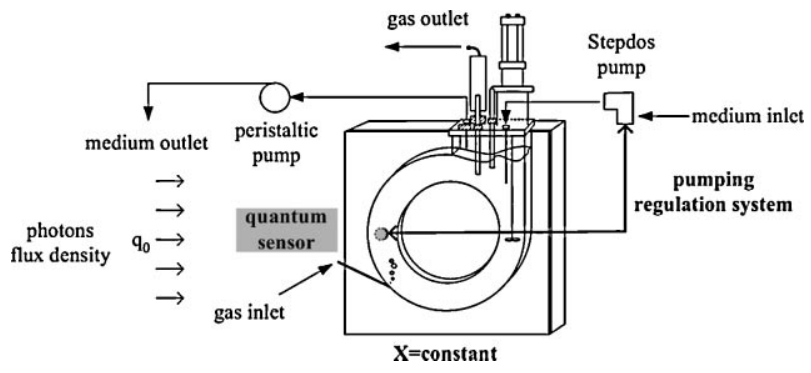

Figure 1. Schematic representation of the photobioreactor operating system in turbidostat mode. same composition as TAP medium except for the carbon source that is inorganic for the MMG while it is organic for the TAP medium. Cultivation was performed under continuous light supply (incident light flux $q_{\mathrm{o}}$ depending on the experiment) and constant stirring (300 rpm). In batch mode, samples were regularly analyzed to follow evolution of the relevant parameters during cultivation. In turbidostat mode (continuous cultures), biomass, sulfate and dilution rate were measured at the steady state. A LI-190SA quantum sensor (LI-COR, Lincoln, NE) has been used for the on-line acquisition of the light flux at the backside of the reactor. By monitoring light attenuation in the reactor, a constant biomass concentration was maintained. This was achieved by injecting fresh growth medium (Stepdos pump 08/S/RC, KNF Neuberger) to dilute the culture when biomass concentration was too high. A peristaltic pump (Masterflex) was used to retrieve medium from the reactor so as to keep a constant culture volume. Experimental set-up is presented in Figure 1. The dilution rate $D\left(\mathrm{~h}^{-1}\right)$ was calculated by dividing measured outlet flow by culture volume.

\section{Biotic and Abiotic Phases Analysis}

For biomass concentration determination, the dry weight has been measured by filtration of the culture sample $(20 \mathrm{~mL})$ through a pre-dried $\left(110^{\circ} \mathrm{C}\right)$ and pre-weighed glass-fiber filter (Whatman GF/F). The filter was next dried, cooled in a dessiccator, and weighed again.

For sulfate concentration, a culture sample was centrifuged $2 \mathrm{~min}$ at 13,000 rpm and the sulfate medium content was measured in the supernatant by ion chromatography (Dionex DX-120, IonPac AS12A anionic column). Eluent was a solution of $\mathrm{Na}_{2} \mathrm{CO}_{3} 270 \mathrm{mM}$ and $\mathrm{NaHCO}_{3} 30 \mathrm{mM}$ (flow setting $=1.5 \mathrm{~mL} \mathrm{~min}^{-1}$ ).

The torus photobioreactor was equipped with a gas analysis system composed of a mass spectrometer (PFEIFFER VACUUM, Saclay, France) and mass flow-meters (ELFLOW devices-Bronkhorst High-Tech, Ruurlo, The Netherlands). This set-up enables on-line measurement of gas released at the photobioreactor outlet (flow rate and gas composition). The gas analysis system was previously described by Fouchard et al. (in press).

\section{Model Assumptions and Description}

\section{Biological Phenomena}

Hydrogen production can be represented as a succession of different stages. Number of stages can vary, depending on the description level, either restricted to global effects of sulfur deprivation (Melis et al., 2000), or with a more detailed description of various metabolic evolutions (Kosourov et al. 2002). Three phases were retained here, as summarized in Figure 2. During a first phase (photosynthetic growth phase), microalgae are placed in 


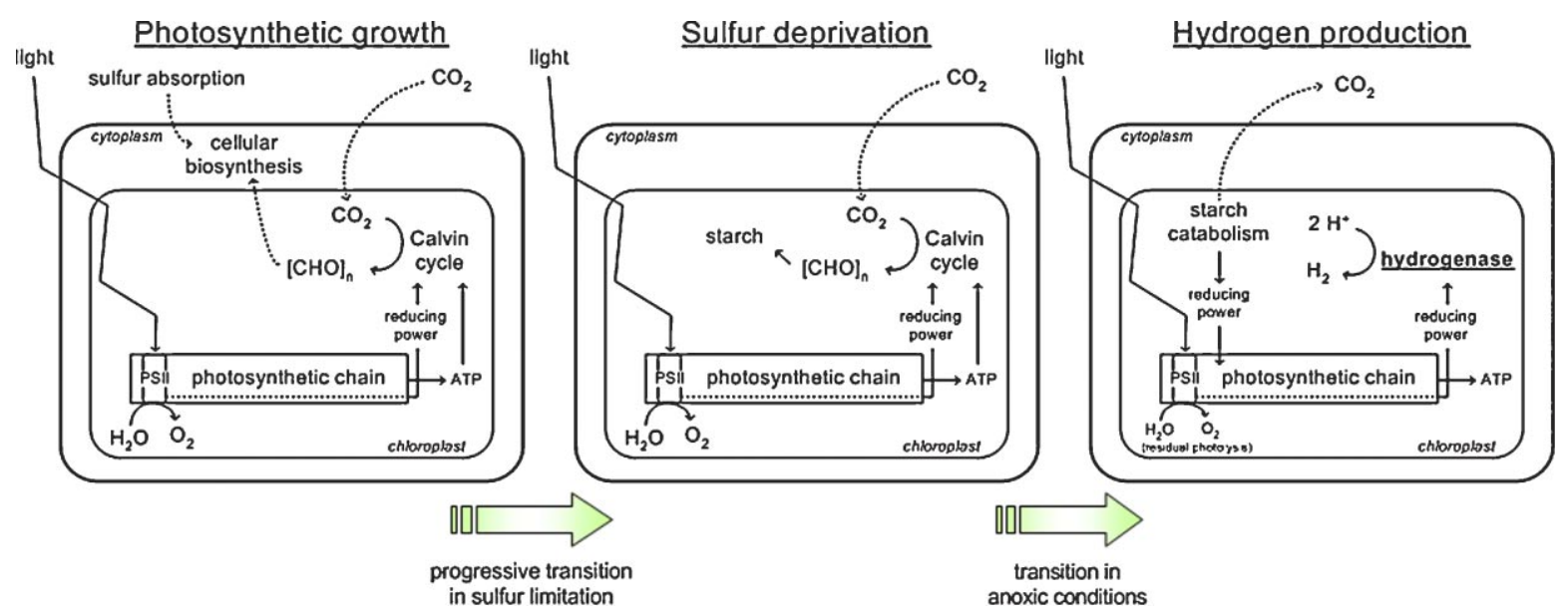

Figure 2. Schematic representation of the biological phenomena involved in the hydrogen production process (adenosine tri-phosphate, ATP). [Color figure can be seen in the online version of this article, available at www.interscience.wiley.com.]

photosynthetic growth conditions. The light-dependent assimilation of inorganic carbon $\left(\mathrm{CO}_{2}\right)$ as well as nutrients $(\mathrm{N}, \mathrm{P}, \mathrm{S}, \mathrm{Mg}, \mathrm{K}, \mathrm{Cl}, \mathrm{Ca} . .$.$) enables cells to form organic$ compounds directly used for their development and multiplication. This is accompanied by oxygen release due to the water photolysis that occurs at the PSII reactional center level. When sulfur deprivation is achieved (marking the beginning of the second phase: sulfur deprivation) naturally by growth consumption of nutrients or by replacing growth medium with a sulfur-deprived one (Kosourov et al., 2005; Laurinavichene et al., 2002, 2006; Melis et al., 2002), specific responses are induced, as an important intracellular starch accumulation during the first days of deprivation. Progressive decrease of PSII activity and thus of $\mathrm{O}_{2}$ release by water photolysis then results in a transition to anoxia. When anoxia conditions are obtained (beginning of the third phase: hydrogen production), hydrogenase is activated and hydrogen production occurs, resulting from both PSII-dependent (based on water photolysis by the PSII residual activity) and independent pathways (based on endogenous substrates degradation like starch).

Photosynthetic activity and its evolution as a consequence of sulfur starvation can be regarded as the driving process of the successive phases leading to the two main conditions favorable to hydrogen production, which are obviously anoxia, but also an over-accumulation of intracellular starch for their contribution in the $\mathrm{H}_{2}$ release. The proposed model focuses on this transition to $\mathrm{H}_{2}$-producing conditions, which corresponds to the first two phases represented in Figure 2 (photosynthetic growth and sulfur deprivation).

\section{Light Transfer in the Photobioreactor}

All previously described phenomena are governed by the available light inside the culture. A radiative model has been used to determine light attenuation inside the reactor. Light transfer, hence irradiance $(G)$ distribution inside the culture, is highly dependent on the photobioreactor geometry. For the torus-shaped one, a complete description can be found in Pottier et al. (2005). The torus-shaped photobioreactor enables the one-dimensional hypothesis to be applied, light attenuation occurring along only one direction namely the depth of culture $z$, perpendicular to the illuminated surface. The two-flux model can then be used because of its efficiency in the case of photosynthetic microorganisms cultivation, where both absorption and scattering of light occur (Cornet et al., 1995, 1998). For the photobioreactor under study, an analytical solution of irradiance distribution is obtained:

$$
G(z)=2 q_{\mathrm{o}} \frac{(1+\alpha) \mathrm{e}^{\delta(L-z)}-(1-\alpha) \mathrm{e}^{-\delta(L-z)}}{(1+\alpha)^{2} \mathrm{e}^{\delta L}-(1-\alpha)^{2} \mathrm{e}^{-\delta L}}
$$

with $\delta=X \sqrt{E_{\mathrm{a}}\left(E_{\mathrm{a}}+2 b E_{\mathrm{s}}\right)}$, the two-flux extinction coefficient, and $\alpha=\sqrt{\left(E_{\mathrm{a}}\right) /\left(E_{\mathrm{a}}+2 b E_{\mathrm{s}}\right)}$ the linear scattering modulus. $E_{\mathrm{a}}$ and $E_{\mathrm{s}}$ are respectively the mass absorption and the mass scattering coefficients $\left(\mathrm{m}^{2} \mathrm{~kg}^{-1}\right)$, and $b$ is the backward scattering fraction (dimensionless). $q_{\mathrm{o}}$ represents the hemispherical incident light flux (or photons flux density, PFD, as commonly named in photobioreactors studies). $X$ represents the biomass concentration inside the photobioreactor $\left(\mathrm{kg} \mathrm{m}^{-3}\right)$.

\section{Kinetic Modeling}

\section{Growth Kinetics}

Numerous kinetic models exist for describing the growth of photosynthetic microorganisms (Aiba, 1982; Muller-Feuga 1998). For eukaryotic cells, growth is the result of the biomass increase by photosynthesis in chloroplast (anabo- 
lism process) and its partial degradation by respiration in mitochondria (catabolism process). The total specific growth rate $\mu$ can thus be expressed as follows:

$$
\mu=\mu_{\mathrm{p}}-\mu_{\mathrm{s}}
$$

where $\mu_{\mathrm{p}}$ and $\mu_{\mathrm{s}}$ describe respectively the photosynthetic and respiration kinetics. This gives in terms of growth volumetric rate:

$$
r_{\mathrm{X}}=\left(\mu_{\mathrm{p}}-\mu_{\mathrm{s}}\right) X=r_{X_{\mathrm{p}}}-r_{X_{\mathrm{s}}}
$$

with $r_{X_{\mathrm{p}}}\left(r_{X_{\mathrm{p}}}=\mu_{\mathrm{p}} X\right)$ and $r_{X_{\mathrm{s}}}\left(r_{X_{\mathrm{s}}}=\mu_{\mathrm{s}} X\right)$ related respectively to the photosynthetic growth and the respiration process.

In this study, the respiration term $\left(\mu_{\mathrm{s}}\right)$ has been assumed to be constant and not affected by the evolution of the culture medium. This was assumed from Melis et al. (2000) who showed that the respiration rate is not significantly affected during the sulfur deprivation, only a slight decrease being observed.

Usually, because microalgae growth is light-limited, the term related to photosynthesis is a function of the light received by the cell, characterized by the available light inside the culture which is represented by the local value of irradiance $G$ (Eq. 1). However, in the special case of sulfur deprivation, it will be also a function of the sulfur available to represent partial inhibition of the PSII. Because cells are able to sustain photosynthetic activity even in total sulfur starvation conditions, this activity is supported thanks to an intracellular sulfur quota. To represent growth rate dependencies on both light and internal sulfur quota, two kinetic models were associated. Light dependency is represented by a photosynthetic growth model with inhibitory term (Andrews, 1968) to characterize the small decrease of growth rate that can be observed for high irradiance (photoinhibition):

$$
\mu_{\mathrm{G}}=\mu_{\max } \frac{G}{K_{\mathrm{I}}+G+\left(G^{2} / K_{\mathrm{II}}\right)}
$$

where $K_{\mathrm{I}}$ is the half-saturation constant and $K_{\mathrm{II}}$ the inhibition constant.

Coupling of the kinetic model of photosynthesis (Eq. 4) with the radiative model (Eq. 1) enables to determine the local photosynthetic response $\mu_{\mathrm{G}}(G(z))$. The average photosynthetic response $\left\langle\mu_{\mathrm{G}}\right\rangle$ calculated all over the reactor volume is obtained by integrating local photosynthetic responses. Because of the one-dimensional light attenuation in the torus photobioreactor, integration is reduced to the direction of the culture depth $z$, which gives:

$$
\left\langle\mu_{\mathrm{G}}\right\rangle=\frac{1}{L} \int_{0}^{L} \mu_{\mathrm{G}}(G(z)) \mathrm{d} z
$$

In the following, \langle\rangle denotes a spatial averaging.
As said before, this model has been completed by a Droop (1968, 1979) model which makes growth a function of available sulfur amount under extracellular and intracellular forms. This important part of the model will be described in details in next section.

\section{Sulfur Kinetics}

Sulfur was considered under its mineral form (sulfate $\mathrm{SO}_{4}^{2-}$ ) in the culture medium, and as an intracellular compound, the concentration of which directly affecting PSII activity and thus photosynthetic growth rate. This intracellular concentration was represented as an intracellular quota $\mathrm{Q}$, following a Droop $(1968,1979)$ formulation, which could be described with a set of macroscopic reactions as follows:

$$
S \stackrel{\left\langle r_{\mathrm{s}}\right\rangle}{\longrightarrow} Q \quad \text { and } \quad Q \stackrel{\left\langle r_{x_{\mathrm{p}}}\right\rangle}{\longrightarrow} X
$$

where $S$ represents extracellular sulfur concentration and $Q$ the intracellular sulfur quota (ratio between intracellular sulfur concentration and biomass concentration).

This formulation is justified by the progressive decrease of PSII activity (several hours) even when a total sulfur starvation is applied at the beginning of the $\mathrm{H}_{2}$-producing protocol (Antal et al., 2003; Wykoff et al., 1998), supporting the hypothesis of an intracellular pool of sulfur (with storage under various forms) that can be remobilized to sustain PSII activity.

Kinetics of the external sulfur consumption is given by $\left\langle r_{\mathrm{S}}\right\rangle$. It is assumed to follow a Monod formulation, as follows:

$$
\left\langle r_{\mathrm{S}}\right\rangle=\left\langle Y_{\mathrm{S} / \mathrm{X}} \mu_{\mathrm{m}}^{\prime} \frac{S X}{K_{\mathrm{S}}+S}\right\rangle=Y_{\mathrm{S} / \mathrm{X}}\left\langle\mu_{\mathrm{m}}^{\prime}\right\rangle \frac{S X}{K_{\mathrm{S}}+S}
$$

$Y_{\mathrm{S} / \mathrm{X}}$ is the yield of substrate conversion representing the uptake rate of the substrate $S$ by produced biomass unit. $\left\langle\mu_{\mathrm{m}}^{\prime}\right\rangle$ is the growth rate obtained without sulfur limitation for given culture conditions. For microalgae, this term is also light-dependent and is thus given by $\left\langle\mu_{\mathrm{m}}^{\prime}\right\rangle=\left\langle\mu_{\mathrm{G}}\right\rangle$ (Eq. 5). $K_{\mathrm{S}}$ represents the half-saturation constant describing the affinity of the organism for the substrate in well-defined conditions.

The intracellular quota $Q$ kinetic is a function of the rate of sulfate absorption $\left\langle r_{\mathrm{S}}\right\rangle$, and of its consumption by photosynthetic activity $\left\langle r_{X_{\mathrm{p}}}\right\rangle$. It must be noticed that in the classical formulation of the Droop model, consumption of intracellular sulfur is set as a function of the total growth rate $\left\langle r_{\mathrm{X}}\right\rangle$. This modification is justified in the present case by the restriction of intracellular sulfur quota to the intracellular part of assimilated sulfur that influences the photosynthetic process by its role on the PSII (and thus influences $r_{X_{\mathrm{p}}}$ ).

Following Droop formulation, it is also necessary to introduce a function $f(Q)$ to represent the intracellular sulfur quota influence on the photosynthetic activity:

$$
\left\langle r_{X_{\mathrm{p}}}\right\rangle=\langle\bar{\mu} f(Q) X\rangle=\langle\bar{\mu}\rangle f(Q) X
$$


with

$$
<\bar{\mu}>f(Q)=<\mu_{\mathrm{p}}>
$$

in which $\bar{\mu}$ is the specific growth rate for a non-limiting value of $Q$ and depends on $f(Q)$ formulation. In the case of non-limiting intracellular sulfur quota, the specific growth rate is only related to light limitation. Indeed if $f(Q)=1$ (as in our model, see next paragraph), $\bar{\mu}=\left\langle\mu_{\mathrm{G}}\right\rangle$ as given by Equations (4) and (5). Light dependency is thus introduced in the Droop formulation, which usually supposes constant illumination.

To complete the formulation of the Droop model, $f(Q)$ has to be specified. For the function $f(Q)$ relating intracellular sulfur quota to growth rate, the following equation is usually applied:

$$
f(Q)=1-\frac{k_{Q}}{Q}
$$

where $k_{\mathrm{Q}}$ is the minimum intracellular sulfur quota. This relation is represented in Figure 3 (dotted line). It was found to give satisfactory results considering the $B_{12}$ vitamin case. However, Equation (9) does not apply to the case of sulfur deprivation. Indeed, as it was observed in Melis et al. (2000) study on hydrogen production under sulfur deprivation, the photosynthetic activity decreases rapidly in the first $20 \mathrm{~h}$ of incubation and next tends towards a low constant value. Equation (9) is not appropriate because it leads to a strong decrease of the growth only for low values of intracellular sulfur quota (Fig. 3), while in our case photosynthesis inhibition occurs rapidly for high intracellular sulfur quota (beginning of deprivation), tending to decrease then for low values of intracellular sulfur quota (residual activity of the PSII). Also, a remaining photosynthetic activity exists when

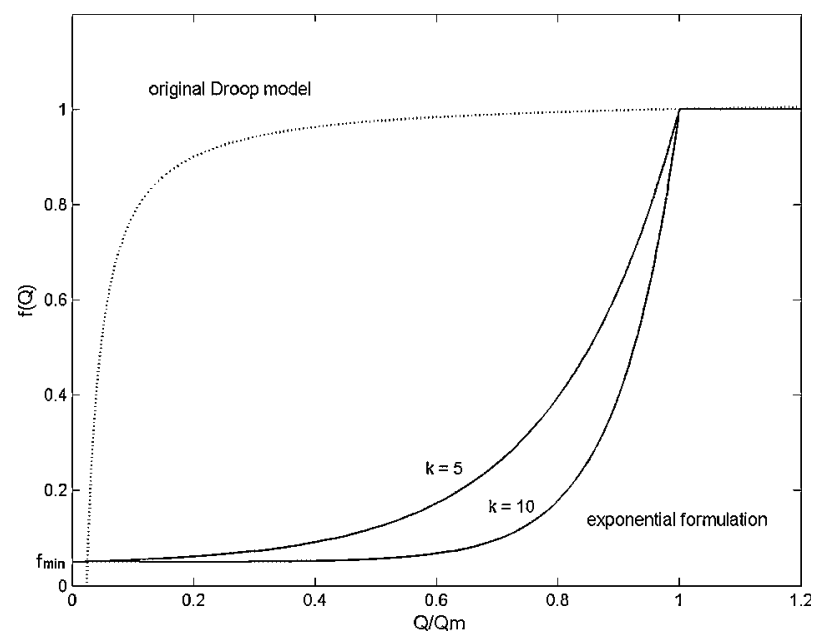

Figure 3. Representation of photosynthetic activity inhibition terms as a function of the intracellular sulfur quota $Q$, for the original Droop model, and for the adapted inhibition function $f(Q)$ given by Equation (10).
$Q$ is equal to zero. A new relation $f(Q)$ has been proposed to reproduce experimentally observed phenomena. It considers an exponential inhibition of the photosynthetic activity towards a minimal non-null value, a sufficient photosynthetic activity being requested to sustain PSIIdependent pathway during hydrogen production phase. This new relation is the following:

$$
\frac{f(Q)-f_{\min }}{1-f_{\min }}=\frac{\exp \left[k\left(Q / Q_{\mathrm{m}}\right)\right]-1}{\exp (k)-1}
$$

with $f(Q)=1$ if $Q>Q_{\mathrm{m}} \cdot Q_{\mathrm{m}}$ represents the maximal quota above which photosynthetic activity is not affected. $f_{\min }$ is the minimal value of $f(Q)$ when $Q$ is null (the residual photosynthetic activity), and $k$ is a fitting constant. Examples of evolution of $f(Q)$ for different values of $k$ are given in Figure 3.

Finally, combining Equation (7) with Equation (3) (if $\mu_{\mathrm{S}}$ assumed to be constant), the total growth rate is represented by:

$$
\left\langle r_{\mathrm{X}}\right\rangle=\left\langle\mu_{\mathrm{G}}\right\rangle f(\mathrm{Q}) X-\mu_{\mathrm{s}} X
$$

with $\left\langle\mu_{\mathrm{G}}\right\rangle$ given by Equation (5).

\section{Starch Accumulation Kinetics}

Starch accumulation appears in experiments as being a sudden phenomenon, explained as a physiological response to mineral limitation (sulfur in this case). Photosynthesis, and more precisely PSII activity, reveals to be essential in starch accumulation. When PSII activity was inhibited, no starch accumulation occurred (even with an organic carbon source like acetate) (Fouchard et al., 2005). Kinetics of starch accumulation was assumed to be totally driven by photosynthesis. To represent the sudden nature of massive starch accumulation in response to mineral limitation, a simple relation based on sulfur available in the medium was introduced. This is based on a biomass partition in starch reserves amount $X_{\mathrm{c}}$ and constitutive biomass representing the remaining part of the biomass $X_{0}$ :

$$
X=X_{0}+X_{\mathrm{c}}
$$

This simple partition is explained by experimental observations, where it was found that starch was essentially accumulated when sulfur deprivation was achieved (Fouchard et al., 2005).

In the sulfur non-limited growth phase, it was assumed that essentially cellular divisions occur and microalgae do not accumulate reserves (or considered to be negligible in comparison with the second phase). During this phase (photosynthetic growth without sulfur limitation), the following equations are applied:

$$
\frac{\mathrm{d} X_{0}}{\mathrm{~d} t}=\frac{\mathrm{d} X}{\mathrm{~d} t} \quad \text { and } \quad \frac{\mathrm{d} X_{\mathrm{c}}}{\mathrm{d} t}=0
$$


A limiting value of sulfur concentration $S_{\text {lim }}$ is introduced to represent sulfur deprivation. When this concentration is reached, cells metabolism is modified: cellular divisions are stopped and starch is accumulated (Ball, 1998; Davies and Grossman, 1998; Grossman, 2000). Photosynthetic metabolism is then considered to entirely sustain starch reserves accumulation, thus using the intracellular sulfur quota. This leads to the following equation (sulfur deprivation phase):

$$
\frac{\mathrm{d} X_{\mathrm{c}}}{\mathrm{d} t}=\frac{\mathrm{d} X}{\mathrm{~d} t} \quad \text { and } \quad \frac{\mathrm{d} X_{0}}{\mathrm{~d} t}=0
$$

\section{Photosynthetic Oxygen Production Kinetics}

To represent transition to anoxia, the model has to describe the evolution of the dissolved oxygen concentration in the photobioreactor. The $\mathrm{O}_{2}$ being produced by photosynthesis and consumed by respiration, net production rate of $\mathrm{O}_{2}$ in the photobioreactor is supposed to be proportional to the growth rate, as follows:

$$
\left\langle r_{\mathrm{O}_{2}}\right\rangle=Y_{\mathrm{O}_{2} / X}\left\langle r_{X}\right\rangle
$$

$Y_{\mathrm{O}_{2} / X}$ is the yield coefficient of $\mathrm{O}_{2}$ conversion. Net production rate of $\mathrm{O}_{2}$ is next used to calculate evolution of dissolved oxygen concentration in the culture, using mass balance as shown in the next section.

\section{Mass Balance Equations}

Evolutions of biomass $X$ and extracellular sulfur $S$ concentrations, intracellular sulfur quota $Q$ and dissolved oxygen concentration $\left[\mathrm{O}_{2}\right]$ are obtained by a mass balance in the photobioreactor, assuming perfectly mixed conditions and thus homogeneous concentrations in the system. The complete set of mass balance equations, describing the photosynthetic growth rate of microalgae in sulfur-limiting conditions is given by:

Total biomass concentration $(X)$ :

$$
\frac{\mathrm{d} X}{\mathrm{~d} t}=<r_{\mathrm{X}}>-D X
$$

Extracellular sulfur concentration $(S)$ :

$$
\frac{\mathrm{d} S}{\mathrm{~d} t}=-\left\langle r_{\mathrm{S}}\right\rangle+D\left(S_{\mathrm{i}}-S\right)
$$

Intracellular sulfur quota $(Q)$ :

$$
\frac{\mathrm{d} Q}{\mathrm{~d} t}=\frac{\left\langle r_{S}\right\rangle-\left\langle r_{X_{\mathrm{p}}}\right\rangle Q}{X}
$$

Dissolved oxygen concentration $\left(\left[\mathrm{O}_{2}\right]\right)$ :

$$
\frac{\mathrm{d}\left[\mathrm{O}_{2}\right]}{\mathrm{d} t}=\left\langle r_{\mathrm{O}_{2}}\right\rangle-k_{\mathrm{L}} a\left(\left[\mathrm{O}_{2}\right]-\left[\mathrm{O}_{2}^{*}\right]\right)-D\left[\mathrm{O}_{2}\right]
$$

In these equations, $S_{i}$ represents the sulfur concentration in the feed, $k_{\mathrm{L}} a$ the specific gas-liquid mass transfer coefficient for oxygen, and $\mathrm{O}_{2}^{*}$ the dissolved oxygen concentration at the equilibrium with the gas phase $\left(\mathrm{O}_{2}^{*}=\right.$ 0 in presence of $\mathrm{N}_{2}$ bubbling). $D$ is the dilution rate. If the photobioreactor is operated in batch mode, $D$ is equal to zero. Volumetric rates $\left\langle r_{\mathrm{s}}\right\rangle,\left\langle r_{X_{\mathrm{p}}}\right\rangle,\left\langle r_{\mathrm{X}}\right\rangle$ and $\left\langle r_{\mathrm{O}_{2}}\right\rangle$ are given by Equations (6), (7), (11), and (15) respectively.

\section{Parameter Identification}

Model parameters can be divided into five groups: the absorption and scattering coefficients $\left(E_{\mathrm{a}}, E_{\mathrm{s}}\right.$, and $\left.b\right)$ of the radiative model, the kinetic model (Haldane) parameters ( $\mu_{\text {max }}, K_{\mathrm{I}}, K_{\mathrm{II}}$, and $\left.\mu_{\mathrm{S}}\right)$, the yield of substrate conversion ( $Y_{\mathrm{S} /}$ $\mathrm{x})$ and the half saturation constant $K_{\mathrm{S}}$, the intracellular sulfur quota kinetic parameters $\left(k, Q_{\mathrm{m}}\right.$ and $\left.f_{\min }\right)$ and the oxygen yield of conversion $\left(Y_{\mathrm{O}_{2} / \mathrm{X}}\right)$ and $k_{\mathrm{L}} a$. Only the optical properties of the radiative model were determined in previous study (Pottier et al., 2005). Identification of the other parameters is presented next. It is important to note that all parameters have been identified from free-acetate media (except for the yield of substrate conversion $Y_{\mathrm{S} / \mathrm{X}}$, that remains unchanged in both free-acetate or acetate media). The classical sulfur-deprivation protocol is indeed usually applied on TAP medium, enriched in acetate, which have specific and potentially complex influences on hydrogen production, but also on standard growth (Heifetz et al., 2000). Furthermore, because an organic carbon source increases the possibility of bacteria contamination, its use will be a hard limitation in the set-up of mass-scale production systems. One short-term objective is to perform $\mathrm{H}_{2}$ production using Chlamydomonas reinhardtii under fully photoautotrophic conditions, although actually such conditions are found less efficient (Fouchard et al., 2005; Tsygankov et al., 2006). It was retained in this study to fit parameters using an acetate-free medium. In the context of $\mathrm{H}_{2}$ production in the presence of acetate, a re-identification of model parameters will be requested, using the same experimental methods as described in this study. In growth conditions, acetate is indeed known to reduce oxygen released by photosynthetic growth, thus facilitating transition to anoxic conditions. The model structure proposed here is still valid (growth dependency on light transfer and intracellular sulfur quota), but values of kinetic parameters (Haldane model) will be certainly modified.

\section{Kinetic Model Parameters $\left(\mu_{\max }, K_{\mathrm{l}}, K_{\mathrm{ll}}\right.$, and $\left.\mu_{\mathrm{S}}\right)$}

To obtain an accurate measurement of the specific growth rate according to the incident light flux, continuous cultures were conducted in turbidostat mode in the torus-shaped photobioreactor. A very low biomass concentration was maintained constant inside the reactor $\left(X<0.1 \mathrm{~g} \mathrm{~L}^{-1}\right)$, enabling to limit light attenuation. The light available in the 
culture (represented by $G$ ) can be different from the incident light flux $\left(q_{0}\right)$. But because error of the predictive radiative transfer model is negligible at low light attenuation, a very accurate estimation of the light received was obtained. It is well-known that at steady state, the dilution rate is equal to the averaged specific growth rate in the reactor (as a consequence of Eq. 16). This allows an accurate determination of the latter value: the reactor volume being known and kept constant, only the measurement of the feeding flow rate is necessary to determine the average growth rate. Measurements were repeated for different incident light flux, up to a radiative flux of $400 \mu \mathrm{mol}$ photon $\mathrm{m}^{-2} \mathrm{~s}^{-1}$ (Pottier, 2005). Because this corresponds to the saturating light for Chlamydomonas reinhardtii, two values issued from Janssen et al. (2000) have been added to illustrate possible interaction between photoinhibition and light access in the photobioreactor. A specific measurement was also done without illumination, to determine the respiration rate. Because such characterization cannot be achieved in continuous mode $(\mu<0)$, it was estimated by measuring the loss in dry weight occurring under dark conditions during a short period (a few hours) of a previously grown culture. Results of experiments are shown in Figure 4.

The kinetic model (Eq. 4) with a maintenance term $\left(\mu_{\mathrm{s}}\right)$ was used to represent experimental data. Identification of the model parameters has been achieved using a multiparameter regression on experimental data that gives $\mu_{\max }=0.2274 \mathrm{~h}^{-1}, K_{\mathrm{I}}=81.38 \mu \mathrm{mol}$ photon $\mathrm{m}^{-2} \mathrm{~s}^{-1}, K_{\mathrm{II}}=$ $2500 \mu$ mol photon $\mathrm{m}^{-2} \mathrm{~s}^{-1}$ and $\mu_{\mathrm{s}}=0.032 \mathrm{~h}^{-1}$.

\section{Yield of Substrate Conversion $\left(\boldsymbol{Y}_{\mathrm{S} / \mathrm{x}}\right)$ and $\boldsymbol{K}_{\mathrm{s}}$ Parameter}

The substrate conversion yield $Y_{\mathrm{S} / \mathrm{X}}$ represents the sulfur uptake during photosynthetic growth. It has been determined following sulfur concentration $\left(\mathrm{SO}_{4}^{2-}\right)$ in the

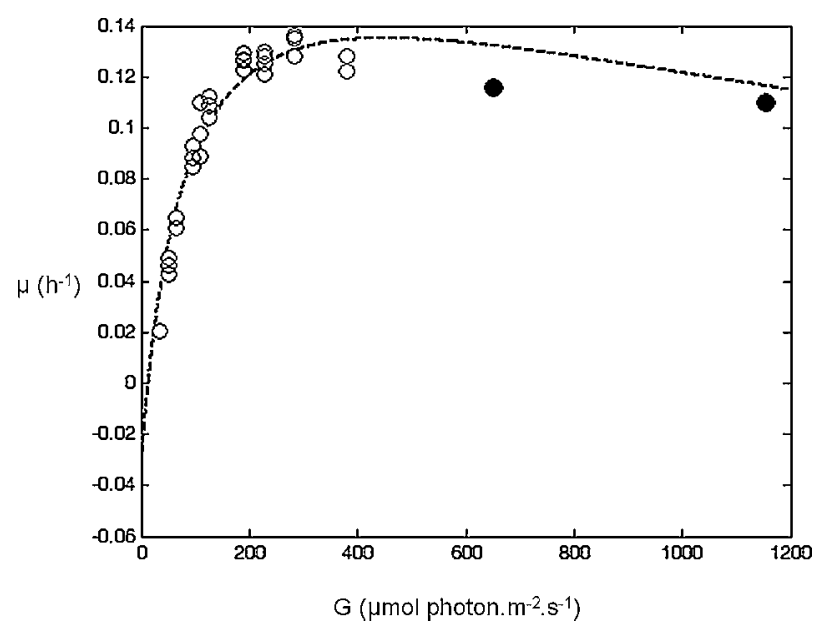

Figure 4. Photosynthetic growth rate of Chlamydomonas reinhardtii (white circles: experimental results obtained in the torus photobioreactor-black circles: additional data obtained from Janssen et al. (2000)—curve: kinetic model fitting). medium during a batch culture in Erlenmeyer. Experiments have been realized with two different initial sulfur concentrations, a non limiting one (standard medium) and a limiting one $\left(5 \mathrm{mg} \mathrm{L}^{-1}\right)$, to test the influence of extracellular sulfur concentration on $Y_{\mathrm{S} / \mathrm{X}}$. Results show that cells modify their capacity of absorption according to sulfur medium concentration (Fig. 5). Yields of conversion are 20.6 and $11.5 \mathrm{mg}$ of sulfates g dry biomass ${ }^{-1}$, respectively for experiments realized in standard and limited medium.

Value of the $K_{\mathrm{S}}$ parameter (Eq. 6) has been identified from data of the sulfates uptake experiment in batch mode under sulfur-limited medium. A global regression gives $K_{\mathrm{S}}=3.7 \mathrm{mg} \mathrm{L}^{-1}$.

\section{Intracellular Sulfur Quota Parameters $\left(k, Q_{m}\right.$, and $\left.f_{\min }\right)$}

For the determination of the intracellular quota parameters $\left(k, Q_{\mathrm{m}}\right.$, and $\left.f_{\min }\right)$, a cultivation has been conducted in the photobioreactor, operated in continuous mode with different sulfur concentrations in the feeding medium. A similar approach was conducted by Fedorov et al. (2005) to experimentally investigate the influence of the sulfur concentration on growth. At the steady state, knowing the sulfur concentration of the feeding medium $S_{\mathrm{i}}$, the biomass concentration $X$ and the sulfur concentration $S$ inside the reactor enables the calculation of the intracellular sulfur quota $Q\left(Q=\frac{S_{i}-S}{X}\right)$. In a first time, non-limiting sulfur concentrations were used to obtain the photosynthetic response to light. In these conditions $f(Q)=1$, and when the steady state is achieved, the model equation for biomass (Eq. 16) gives $\bar{\mu}-\mu_{\mathrm{s}}=D$. The photosynthetic response $\bar{\mu}$ (not affected by $Q$ ), is directly obtained from the measurement of the dilution rate ( $\mu_{\mathrm{S}}$ is supposed to be known). Then, experiments were performed with sulfur-limited media. The turbidostat mode was preferred in this study to the

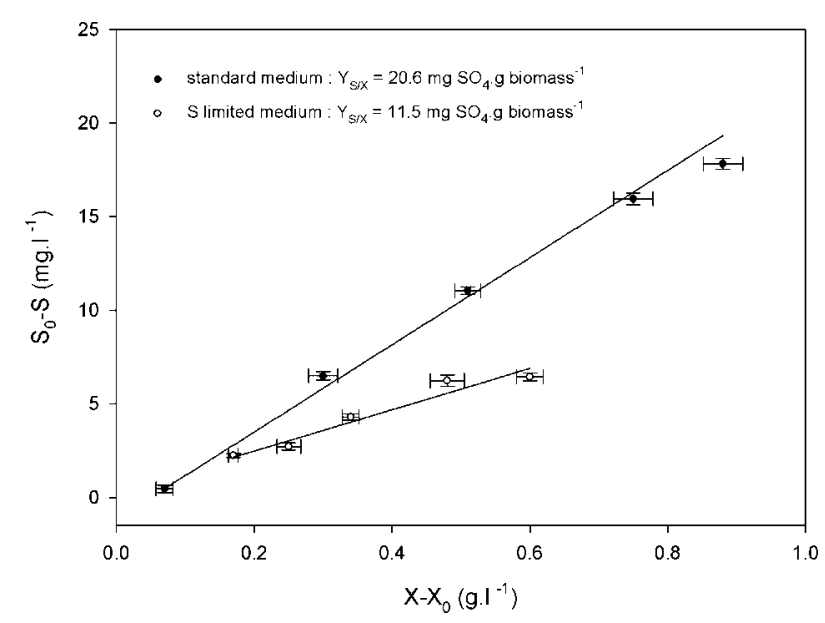

Figure 5. Sulfur uptake according to the change in biomass for a discontinuous culture of Chlamydomonas reinhardtii under standard and sulfur limited media $\left(q_{0}=245 \mu \mathrm{mol}\right.$ photon $\left.\mathrm{m}^{-2} \mathrm{~s}^{-1}\right)$. 
chemostat one, as used by Fedorov et al. (2005). By adjusting the dilution rate $D$, the culture conducted in turbidostat mode enables to maintain biomass concentration and thus light transfer conditions. The photosynthetic response $\bar{\mu}$ therefore remains unchanged. This leads to $D=\bar{\mu} f(Q)-\mu_{s}$. So all values are known except $f(\mathrm{Q})$. The dilution rate varies thus according to the sulfur-dependent growth. Results of experiments are shown in Figure 6. Sulfur concentration revealed to influence light-limited growth below a value around $12 \mathrm{mg} \mathrm{L}^{-1}$. The exact same value was observed by Fedorov et al. (2005). Values of the characteristic parameters of the function $f(Q): k, Q_{\mathrm{m}}$, and $f_{\min }$, were obtained by regression on the experimental data (Fig. 7). Following values have been obtained: $k=0.3389, Q_{\mathrm{m}}=7 \mathrm{mg} \mathrm{SO}_{4}^{2-} \mathrm{g}$ biomass $^{-1}$ and $f_{\min }=0.0674$.

\section{Yield of Oxygen Conversion $\left(\boldsymbol{Y}_{\mathbf{O}_{\mathbf{2}} / \mathbf{x}}\right)$}

The yield of conversion $Y_{\mathrm{O}_{2} / \mathrm{X}}$ was determined by measuring oxygen release simultaneously to the change in biomass during a standard photosynthetic growth, for a batch culture conducted in the torus photobioreactor (using a standard growth medium, without sulfur limitation). Results are shown in Figure 8. This gives a $Y_{\mathrm{O}_{2} / \mathrm{X}}$ value equal to 1.42 g oxygen biomass $^{-1}$.

\section{Specific Gas-Liquid Mass Transfer Coefficient for Oxygen $\left(k_{\mathrm{L}} a\right)$}

$k_{\mathrm{L}} a$ was determined experimentally in the torus photobioreactor, using a "gassing-in" method (Moser, 1988). After a period of deoxygenation by bubbling the liquid medium with nitrogen gas, a $10 \mathrm{~mL} \mathrm{~min}^{-1}$ air flow was applied inside the reactor. The rate of gas transfer to the liquid was measured with a dissolved oxygen sensor (Mettler

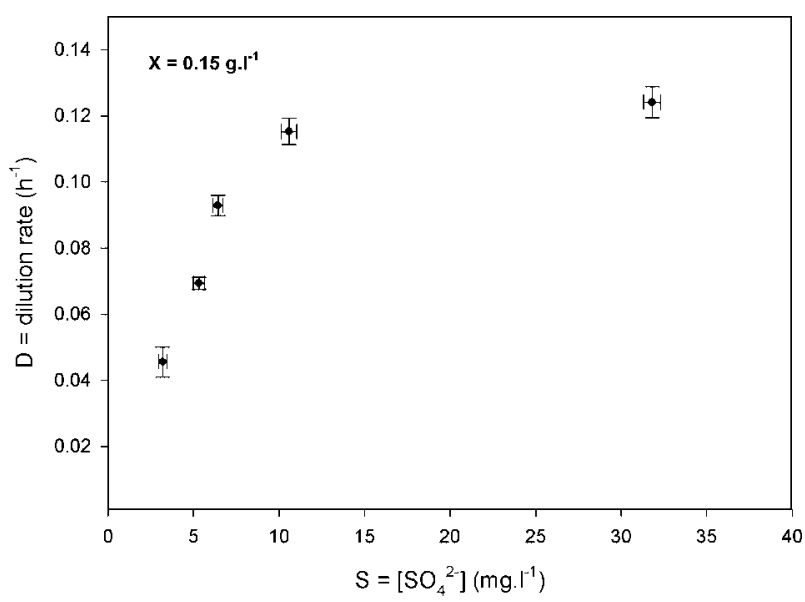

Figure 6. Effect of the sulfur medium content on the Chlamydomonas reinhardtii growth. $S$ and $D$ have been measured in steady state conditions $\left(q_{0}=245 \mu \mathrm{mol}\right.$ photon $\mathrm{m}^{-2} \mathrm{~s}^{-1}$ ).

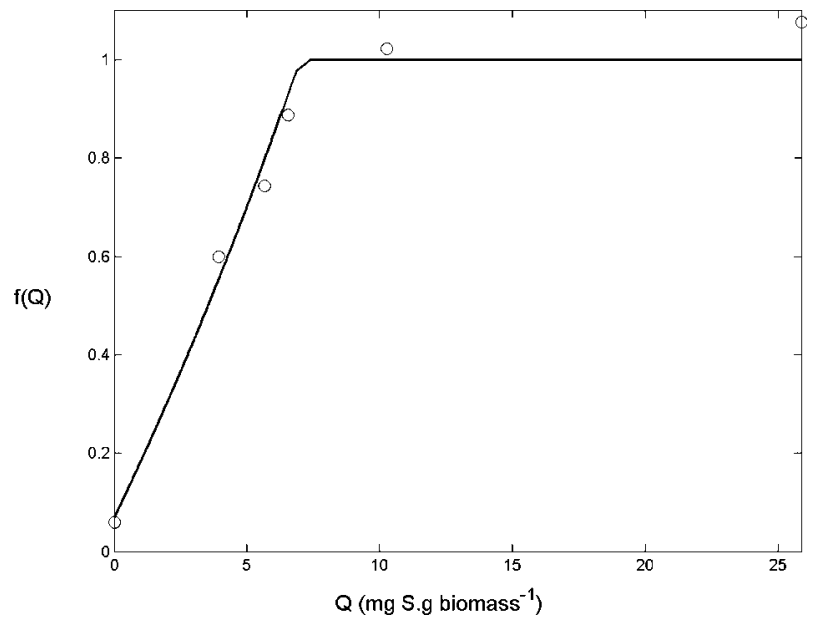

Figure 7. Representation of the function $f(Q)$ obtained by regression on the experimental points according to the intracellular sulfur quota $Q$.

Toledo InPro 6800 series $\mathrm{O}_{2}$ ). $k_{\mathrm{L}} a$ coefficient was then determined by oxygen mass balance in the liquid phase using the following equation:

$$
\frac{\mathrm{d}[\mathrm{O} 2]}{\mathrm{d} t}=k_{\mathrm{L}} a\left(\mathrm{O}_{2}^{*}-\left[\mathrm{O}_{2}\right]\right)
$$

and after integration

$$
\ln \frac{\left(\mathrm{O}_{2}^{*}-\left[\mathrm{O}_{2}\right]\right)}{\left(\mathrm{O}_{2}^{*}-\left[\mathrm{O}_{2}\right]_{0}\right)}=k_{\mathrm{L}} a \cdot t
$$

$\mathrm{O}_{2}^{*}\left(8.76 \mathrm{mg} \mathrm{L}^{-1}\right)$ was obtained after $24 \mathrm{~h}$ of air bubbling. The estimated value of $k_{\mathrm{L}} a$, determined by regression is $0.46 \mathrm{~h}^{-1}$.

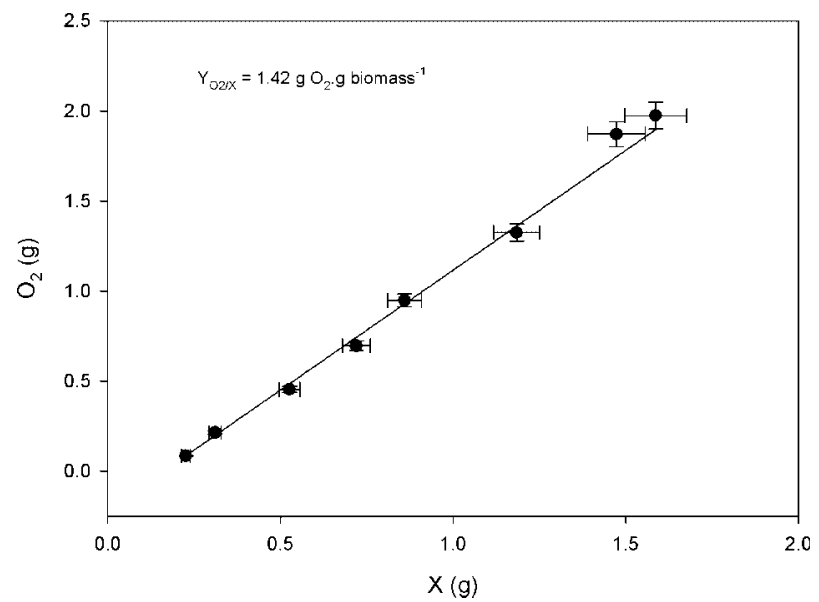

Figure 8. Oxygen gas release according to the change in biomass for a discontinuous culture of Chlamydomonas reinhardtii under standard medium $\left(q_{0}=300 \mu \mathrm{mol}\right.$ photon $\left.\mathrm{m}^{-2} \mathrm{~s}^{-1}\right)$. 
Table I. Model parameters.

\begin{tabular}{|c|c|c|c|}
\hline Group & Parameter & Value & Unit \\
\hline Radiative model & $\begin{array}{c}E_{\mathrm{a}} \\
E_{\mathrm{s}} \\
b\end{array}$ & $\begin{array}{l}172 \\
868 \\
0.01728\end{array}$ & $\begin{array}{l}\mathrm{m}^{2} \mathrm{~kg}^{-1} \\
\mathrm{~m}^{2} \mathrm{~kg}^{-1}\end{array}$ \\
\hline Kinetic model & $\begin{array}{c}\mu_{\max } \\
K_{\mathrm{I}} \\
K_{\mathrm{II}} \\
\mu_{\mathrm{s}}\end{array}$ & $\begin{array}{c}0.2274 \\
81.38 \\
2500 \\
0.032\end{array}$ & $\begin{array}{c}\mathrm{h}^{-1} \\
\mu \mathrm{mol} \text { photon } \mathrm{m}^{-2} \mathrm{~s}^{-1} \\
\mu \mathrm{mol} \text { photon } \mathrm{m}^{-2} \mathrm{~s}^{-1} \\
\mathrm{~h}^{-1}\end{array}$ \\
\hline Yield of substrate conversion & $\begin{array}{l}Y_{\mathrm{S} / \mathrm{X}} \text { standard medium } \\
Y_{\mathrm{S} / \mathrm{X}} S \text { limited medium }\end{array}$ & $\begin{array}{l}20.6 \\
11.5\end{array}$ & $\begin{array}{l}\mathrm{mgSO}_{4}^{2-} \mathrm{gX}^{-1} \\
\mathrm{mgSO}_{4}^{2-} \mathrm{gX}^{-1}\end{array}$ \\
\hline Kinetic of intracellular sulfur quota & $\begin{array}{c}k \\
Q_{\mathrm{m}} \\
f_{\min } \\
K_{\mathrm{S}}\end{array}$ & $\begin{array}{l}0.3389 \\
7 \\
0.0674 \\
3.7\end{array}$ & $\begin{array}{c}\operatorname{mgSgX^{-1}} \\
\mathrm{mg} \mathrm{L}^{-1}\end{array}$ \\
\hline $\begin{array}{l}\text { Yield of oxygen conversion } \\
\text { Specific gas-liquid mass transfer coefficient for oxygen }\end{array}$ & $\begin{array}{c}Y_{\mathrm{O}_{2} / \mathrm{x}} \\
k_{\mathrm{L}} a\end{array}$ & $\begin{array}{l}1.42 \\
0.46\end{array}$ & $\begin{array}{c}\mathrm{gO}_{2} \mathrm{gX}^{-1} \\
\mathrm{~h}^{-1}\end{array}$ \\
\hline
\end{tabular}

Results of the parameters identification are summarized in Table I.

\section{Model Behavior and Sensitivity Analysis}

To illustrate model dynamics, simulations were done using Matlab 7.5.0 (R2007b) software (The MathWorks, Inc.,
Natick, MA). The differential equations system was integrated using the Ordinary Differential Equation (ODE) solver "ode15s". Simulations results performed in batch cultivation are reported in Figures 9-12. The initial conditions used to initiate the simulation, reported in Table II are representative of the experimental conditions leading to hydrogen production. Figure 9 shows the
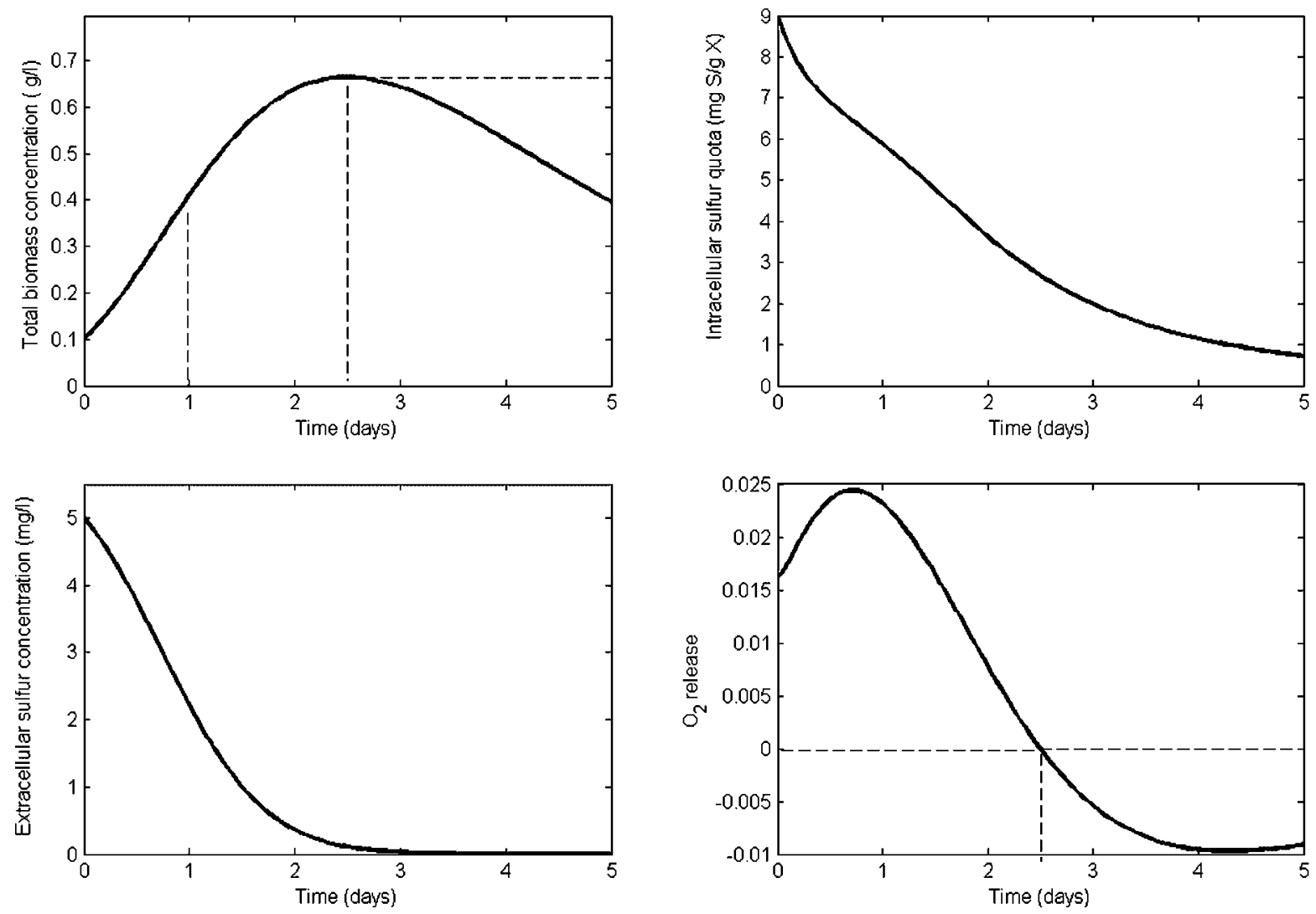

Figure 9. Simulation results for total biomass, extracellular sulfur concentration, intracellular sulfur quota and $0_{2}$ released in batch cultivation. $S_{0}=5 \mathrm{mg} \mathrm{L}^{-1}, X_{0}=0.1 \mathrm{~g} \mathrm{~L}^{-1}$ and $q_{0}=110 \mu \mathrm{mol}$ photon $\mathrm{m}^{-2} \mathrm{~s}^{-1}$. 


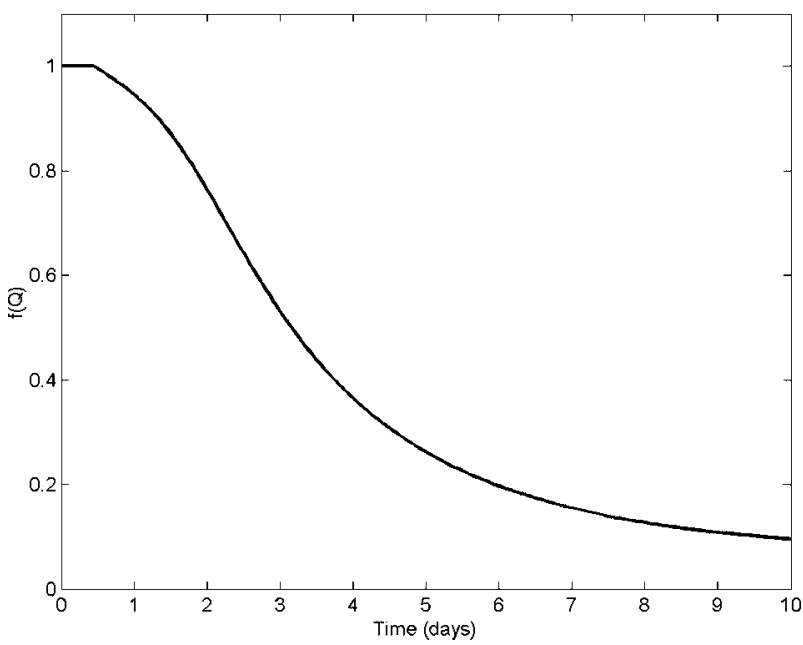

Figure 10. Simulation results for the change in photosynthetic activity with time, in batch cultivation.

evolution of extracellular and intracellular sulfur concentrations, total biomass and $\mathrm{O}_{2}$ concentration. The sulfur deprivation and light limitation effects on growth kinetics are illustrated in Figures 10 and 11, respectively. During the first day of cultivation, the intracellular sulfur concentration is not growth limiting $(f(Q)=1)$, and $\mathrm{O}_{2}$ accumulates in the photobioreactor. In the second day of cultivation, the photosynthetic activity of the microalgae becomes limited by the intracellular sulfur quota (Fig. 10), which progressively decreases (the extracellular sulfur absorption rate in the cell becomes smaller than the intracellular sulfur quota consumption rate). The sulfur deprivation conditions are reached and the photosynthetic activity decreases bellow the

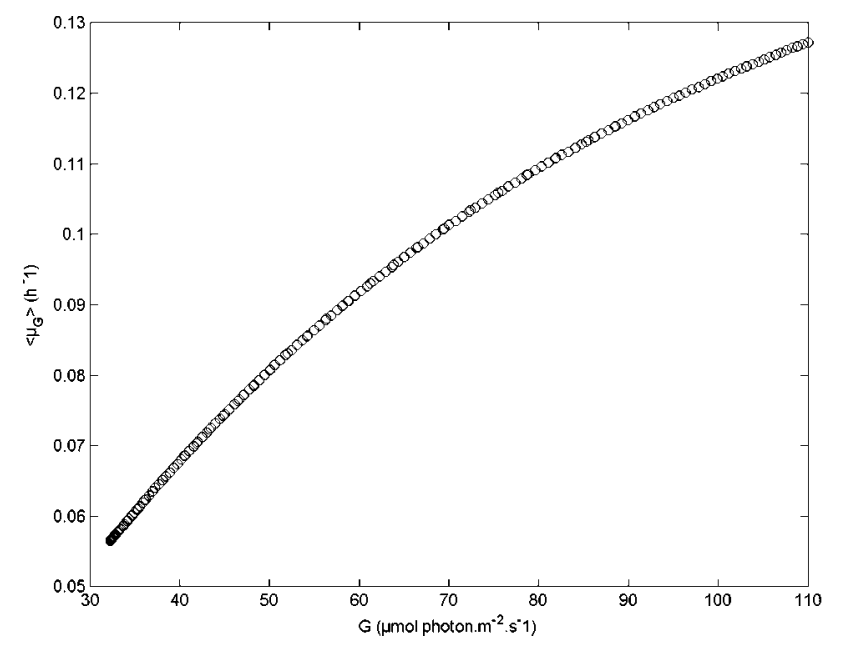

Figure 11. Simulation results for $\left\langle\mu_{G}\right\rangle$ as a function of the mean irradiance $G$, in batch cultivation.

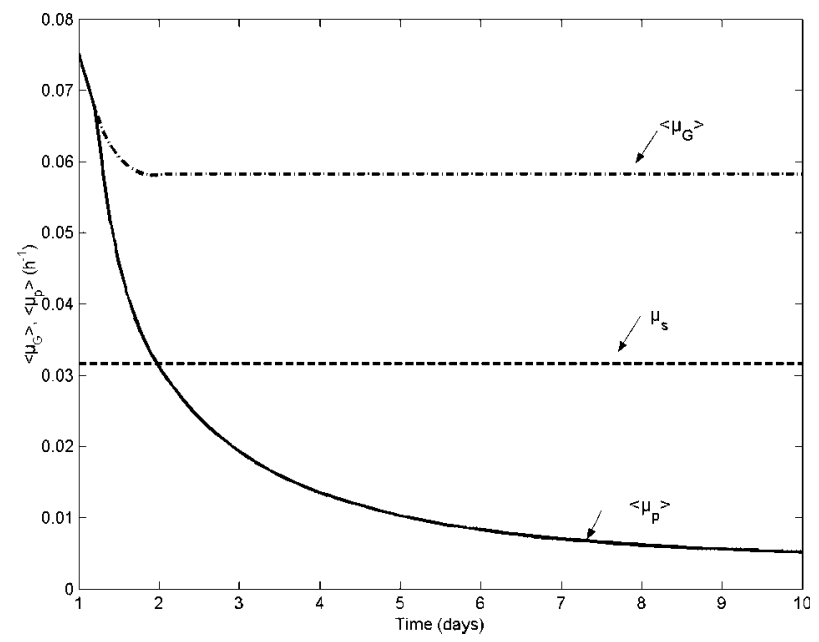

Figure 12. Evolution of $\left\langle\mu_{\mathrm{G}}\right\rangle$ and $\left\langle\mu_{\mathrm{p}}\right\rangle$ with time, in batch cultivation. Simulation results.

value of the respiration rate (Fig. 12). As a consequence, the $\mathrm{O}_{2}$ concentration in the medium progressively diminishes and anoxic conditions are established after 2.5 days of cultivation. The photosynthetic growth rate becoming smaller than the maintenance term (Fig. 12), the total biomass concentration progressively decreases.

The model includes eight kinetic and yield parameters $\left(K_{\mathrm{S}}, \mu_{\max }, Y_{\mathrm{S} / \mathrm{X}}, Y_{\mathrm{O}_{2} / \mathrm{X}}, k, f_{\min }, Q_{\mathrm{m}}, \mu_{\mathrm{s}}\right)$ identified from experimental data obtained with different experiments (see identification section). In this section, the model sensitivity to these parameters is studied. The dynamic evolution of the main model variables as illustrated in Figure 9, was used as a "reference trajectory" for studying the model sensitivity to its parameters. As mentioned above, the initial conditions and the set of parameters chosen to conduct this reference simulation correspond to the normal conditions leading to the hydrogen production in photobioreactor. Those parameters and initial conditions are presented in Tables I and II. Then, numerical simulations were performed with varying parameter variations. A sensitivity function $\left(\sigma_{\mathrm{y}}^{p}(t)\right)$ was calculated as follows:

$$
\sigma_{\mathrm{y}}^{p}(t)=\frac{y\left(p+\Delta p, y_{0}, u, t\right)-y\left(p, y_{0}, u, t\right)}{y\left(p, y_{0}, u, t\right)}
$$

where $y\left(p, y_{0}, u, t\right)$ represents the simulated value at time $t$ of variable $y$ associated with parameter $p$, initial conditions

Table II. Initial conditions for the calculation of reference trajectory.

\begin{tabular}{lcll}
\hline Initial condition and inputs & Value & \multicolumn{1}{c}{ Unit } \\
\hline Initial biomass concentration $X_{0}$ & 0.07 & $\mathrm{~g} \mathrm{~L}^{-1}$ \\
Initial extracellular sulfur concentration $S_{0}$ & 5 & $\mathrm{mg} \mathrm{L}^{-1}$ \\
Initial intracellular sulfur quota $Q_{0}$ & 9 & $\mathrm{mg} \mathrm{S} \mathrm{X} \mathrm{X}^{-1}$ \\
Incident light flow $q_{0}$ & 110 & $\mu \mathrm{mol} \mathrm{photon} \mathrm{m}^{-2} \mathrm{~s}^{-1}$ \\
\hline
\end{tabular}



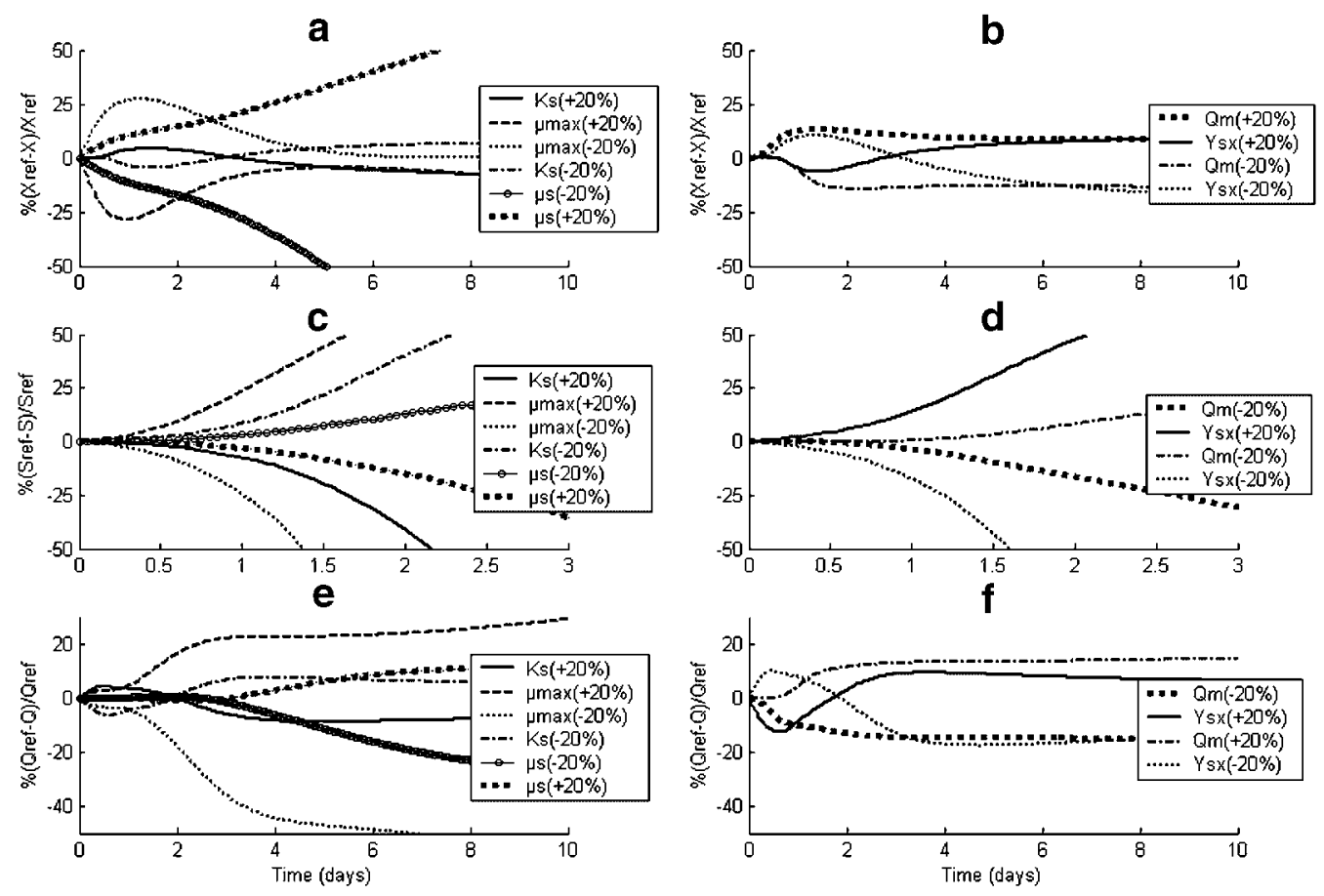

Figure 13. Evolution with time of sensitivity functions of $X, S$, and $Q$ associated with model parameters $\mu_{\max ,}, Y_{\mathrm{S} / \mathrm{X}}, Q_{\mathrm{m}}, \mu_{\mathrm{s}}$, and $K_{\mathrm{S}}$.

$y_{0}$ and input $u$. As the objective here was to determine the precision with which each parameter has to be estimated, in the sequel, we have focused on the analysis results with $\pm 20 \%$ of parameters variations. Results in Figure 13 show the sensitivity functions for three main model variables: $X$ (total biomass concentration), $S$ (substrate concentration) and $Q$ (intracellular sulfur quota) associated to the parameters $\mu_{\max }, Y_{\mathrm{S} / \mathrm{X}}, Q_{\mathrm{m}}, \mu_{\mathrm{s}}$, and $K_{\mathrm{s}}$. For all other parameters, the corresponding sensitivity function was less than $5 \%$. As illustrated in Figure 13a and b, parameters $\mu_{\max }$ and $\mu_{\mathrm{s}}$ are the most significant on the changes of variable $X$. The sensitivity function associated with $20 \%$ variation of these parameters is about $25 \%$ during the entire batch. As expected, the sensitivity function related to $\mu_{\max }$ reaches its maximal value in the first day of cultivation (photosynthetic growth phase) while $\mu_{\mathrm{s}}$ parameter becomes more sensitive in sulfur-deprived conditions. Twenty percent variations of $Q_{\mathrm{m}}$ and $Y_{\mathrm{S} / \mathrm{X}}$ parameters have less influence on the biomass changes, with a sensitivity function about $12 \%$ during exponential phase and about $5 \%$ at the end of the batch. Concerning the sensitivity of $S$ with the same parameters, its sensitivity functions are increasing during the batch (Fig. 13c and d). All parameters are equally significant for the extracellular sulfur concentration after one day of cultivation when the culture medium becomes sulfur-limited. The influence of model parameters variations on the changes of intracellular sulfur quota was illustrated in Figure $13 \mathrm{e}$ and $\mathrm{f}$. As for extracellular sulfur concentration, the sensitivity functions are significant after 2.5 days of cultivation, but their values are lower than $40 \%$.

In conclusion, it results that $\mu_{\max }, \mu_{\mathrm{s}}$ are the most significant parameters; they have to be carefully identified in order to guarantee good model prediction for $X$ and $S$ variables. The same observation can be made for $Y_{\mathrm{S} / \mathrm{X}}$, especially with respect to the $S$ variable. $Q_{\mathrm{m}}$ and $K_{\mathrm{S}}$ parameter have little influence on the model, according to their contribution to it (Eqs. 6 and 10).

\section{Conclusion}

In this article, a model of practical interest for predicting culture changes towards $\mathrm{H}_{2}$-producing conditions has been proposed. It represents sulfur deprivation induction (based on photosynthetic growth) and the two main processes leading to hydrogen production in Chlamydomonas reinhardtii, which are over-accumulation of intracellular starch and progressive reduction of PSII activity for anoxia achievement. Key features of the model are presented. An experimental identification procedure has been developed for each model parameter. By using either chemostat or turbidostat mode, effects of light and sulfur limitation have been decoupled from each other, thereby enabling identification of all parameters of the model and understanding the role of each parameter on the dynamical evolution of the photobioreactor. Additionally, a sensitivity analysis of the model to its parameters has been done, providing the most sensitive parameters for which special 
attention has to be paid during the identification procedure.

Model validation and its capacity to determine new protocols for $\mathrm{H}_{2}$ production in photobioreactor under optimized conditions will be presented in Part II of this paper.

\section{Nomenclature}

$b \quad$ backward scattering fraction

$D \quad$ dilution rate $\left(\mathrm{h}^{-1}\right)$

$E_{\mathrm{a}} \quad$ mass absorption coefficient $\left(\mathrm{m}^{2} \mathrm{~kg}^{-1}\right)$

$E_{\mathrm{s}} \quad$ mass scattering coefficient $\left(\mathrm{m}^{2} \mathrm{~kg}^{-1}\right)$

$f_{\min } \quad$ minimal value for $f(Q)$

$f(Q) \quad$ inhibition of the photosynthetic activity

G irradiance (mol photon $\mathrm{m}^{-2} \mathrm{~s}^{-1}$ )

$k \quad$ constant (Equation 10)

$k_{\mathrm{L}} a \quad$ specific gas-liquid mass transfer coefficient for oxygen $\left(\mathrm{h}^{-1}\right)$

$k_{\mathrm{Q}} \quad$ minimum intracellular sulfur quota $\left(\mathrm{gS} \mathrm{g}_{\text {biomass }}{ }^{-1}\right)$

$K_{\mathrm{S}} \quad$ half saturation constant of growth kinetics $\left(\mathrm{g} \mathrm{L}^{-1}\right)$

$K_{\mathrm{I}} \quad$ half-saturation constant (mol photon $\mathrm{m}^{-2} \mathrm{~s}^{-1}$ )

$K_{\mathrm{II}} \quad$ inhibition constant of growth kinetics (mol photon $\mathrm{m}^{-2} \mathrm{~s}^{-1}$ )

L photobioreactor depth (m)

$\mathrm{O}_{2}^{*} \quad$ dissolved oxygen saturation concentration at the equilibrium with the gas phase $\left(\mathrm{g} \mathrm{L}^{-1}\right)$

$\left[\mathrm{O}_{2}\right]$ dissolved oxygen concentration $\left(\mathrm{g} \mathrm{L}^{-1}\right)$

p model parameter (Equation 21)

Q intracellular sulfur quota $\left(\mathrm{gS} \mathrm{g} \mathrm{biomass}^{-1}\right)$

$Q_{\mathrm{m}} \quad$ maximal intracellular sulfur quota above which one photosynthetic activity is not affected ( $\mathrm{g} \mathrm{S} \mathrm{g} \mathrm{biomass}^{-1}$ )

incident light flow (mol photon $\mathrm{m}^{-2} \mathrm{~s}^{-1}$ )

$r_{\mathrm{O}_{2}}$ net production rate of oxygen $\left(\mathrm{g} \mathrm{O}_{2} \mathrm{~L}^{-1} \mathrm{~h}^{-1}\right)$

$r_{\mathrm{S}} \quad$ external sulfur consumption rate $\left(\mathrm{g} \mathrm{S} \mathrm{L}^{-1} \mathrm{~h}^{-1}\right)$

$r_{\mathrm{X}} \quad$ growth volumetric rate $\left(\mathrm{g} \mathrm{X} \mathrm{L}^{-1} \mathrm{~h}^{-1}\right)$

$r_{X_{\mathrm{p}}} \quad$ photosynthetic growth volumetric rate $\left(\mathrm{gX} \mathrm{L}^{-1} \mathrm{~h}^{-1}\right)$

$r_{X_{\mathrm{S}}} \quad$ respiratory volumetric rate $\left(\mathrm{gX} \mathrm{L}^{-1} \mathrm{~h}^{-1}\right)$

$S \quad$ substrate concentration $\left(\mathrm{g} \mathrm{L}^{-1}\right)$

$S_{\mathrm{i}} \quad$ initial substrate concentration $\left(\mathrm{g} \mathrm{L}^{-1}\right)$

$S_{\lim } \quad$ substrate limiting concentration $\left(\mathrm{g} \mathrm{L}^{-1}\right)$

$t \quad$ time

$u \quad$ input variable (Equation 21)

$X \quad$ biomass $\left(\mathrm{g} \mathrm{L}^{-1}\right)$

$X_{\mathrm{c}} \quad$ starch reserves $\left(\mathrm{g} \mathrm{L}^{-1}\right)$

$X_{0} \quad$ constitutive biomass $\left(\mathrm{g} \mathrm{L}^{-1}\right)$

$y \quad$ variable (Equation 21)

$y_{0} \quad$ initial value of $y$ variable

$Y_{\mathrm{O}_{2} / \mathrm{X}}$ yield of oxygen conversion $\left(\mathrm{g} \mathrm{O}_{2}\right.$ g biomass $\left.^{-1}\right)$

$Y_{\mathrm{S} / \mathrm{X}} \quad$ yield of substrate conversion $\left(\mathrm{g} \mathrm{g} \mathrm{g} \mathrm{biomass}^{-1}\right)$

$z \quad$ culture depth $(\mathrm{m})$

$Z \quad$ local depth (m)

\langle\rangle$\quad$ denotes a spatial averaging

\section{Greek letters}

$\alpha \quad$ linear scattering modulus

$\delta \quad$ two-flux extinction coefficient $\left(\mathrm{m}^{-1}\right)$ $\mu \quad$ specific growth rate $\left(\mathrm{h}^{-1}\right)$

$\bar{\mu} \quad$ specific growth rate for a non-limiting quota $Q\left(\mathrm{~h}^{-1}\right)$

$\mu_{\mathrm{G}} \quad$ local photosynthetic response $\left(\mathrm{h}^{-1}\right)$

$\mu_{\max }$ maximal specific growth rate $\left(\mathrm{h}^{-1}\right)$

$\mu_{\mathrm{m}}^{\prime} \quad$ specific growth rate for a non-limiting sulfur concentration $\left(\mathrm{h}^{-1}\right)$

$\mu_{\mathrm{p}} \quad$ photosynthetic growth rate $\left(\mathrm{h}^{-1}\right)$

$\mu_{\mathrm{s}} \quad$ rate of respiration $\left(\mathrm{h}^{-1}\right)$

$\sigma \quad$ sensitivity function of $y$ variable with $p$ parameter

This work was supported by the Interdisciplinary CNRS Energy Program (2002-2005), by the CPER-Etat-Region of Pays de la Loire (France) and by the "PhotobioH2" ANR Program (French National Program, 2006-2009).

\section{References}

Aiba S. 1982. Growth kinetics of photosynthetic microorganisms. Adv Biochem Eng Biotechnol 23:85-156.

Akkerman I, Janssen M, Rocha J, Reith J, Wijffels R. 2003. Photobiological hydrogen production: Photochemical efficiency and bioreactor design. In: Reith J, Wijffels R, Barten H, editors. Bio-methan and biohydrogen. The Netherlands: Dutch Biological Hydrogen Foundation. pp. 124-145.

Andrews J. 1968. A mathematical model for the continuous culture of microorganisms utilizing inhibitory substrates. Biotechnol Bioeng 10:707-723.

Antal TK, Kredeleva TE, Laurinavichene TV, Makarova VV, Ghirardi ML, Rubin AB, Tsygankov A, Seibert M. 2003. The dependence of algal $\mathrm{H}_{2}$ production on photosystem II and $\mathrm{O}_{2}$ consumption activities in sulfurdeprived Chlamydomonas reinhardtii cells. Biochim Biophys Acta 1607: 153-160.

Asada Y, Miyake J. 1999. Photobiological hydrogen production. J Biosci Bioeng 88:1-6.

Ball S. 1998. Regulation of starch biosynthesis. In: Rochaix J, GoldschmidtClermont M, Merchant S, editors. The molecular biology of Chlamydomonas. The Netherlands: Kluwer, Dordrecht. pp. 549-567.

Benemann JR, Berenson J, Kaplan N, Kauren M. 1973. Hydrogen evolution by a chloroplast-ferredoxin-hydrogenase system. Proc Natl Acad Sci USA 70:2317-2320.

Bernard O, Sciandra A, Madani S. 2007. Multimodel analysis of the response of the coccolithophore Emiliania huxleyi to an elevation of $\mathrm{pCO}_{2}$ under nitrate limitation. Ecol Model 211:324-338.

Cornet JF, Dussap CG, Dubertret G. 1992. A structured model for simulation of cultures of the cyanobacterium Spirulina plantesis in photobioreactors: I. Coupling between light transfer and growth kinetics. Biotechnol Bioeng 40:817-825.

Cornet JF, Dussap CG, Gros JB. 1995. Conversion of radiant light energy in photobioreactors. AICHE J 40:1055-1066.

Cornet JF, Dussap CG, Gros JB. 1998. Kinetics and energetics of photosynthetic micro-organisms in photobioreactors: Application to Spirulina growth. Adv Biochem Eng Biot 59:155-224.

Csögör Z, Herrenbauer M, Perner I, Schmidt K, Posten C. 1999. Design of a photo-bioreactor for modelling purposes. Chem Eng Process 38:517523.

Das D, Veziroglu NT. 2001. Hydrogen production by biological processes: A survey of literature. Int J Hydrogen Energ 26:13-28.

Davies JD, Grossman AR. 1998. Responses to deficiencies in macronutrients. In: Rochaix J, Goldschmidt-Clermont M, Merchant S, editors. The molecular biology of Chlamydomonas. The Netherlands: Kluwer, Dordrecht. pp. 613-635.

Droop M. 1968. Vitamin B12 and marine ecology IV. The kinetics of uptake growth and inhibition in Monochrysis lutheri. J Marine Biol Assoc UK 48:689-733. 
Droop M. 1979. On the definition of X and Q in the cell quota model. J Exp Mar Biol Ecol 39:203.

Fedorov AS, Kosourov S, Ghirardi ML, Seibert M. 2005. Continuous production by Chlamydomonas reinhardtii using a novel twostage, sulfate-limited chemostat system. Appl Bioch Biotech 124: 403-412.

Fouchard S, Hemschemeier A, Caruana A, Pruvost J, Legrand J, Happe T, Peltier G, Cournac L. 2005. Autotrophic and mixotrophic hydrogen photoproduction in sulfur-deprived Chlamydomonas cells. Appl Environ Microb 71:6199-6205.

Fouchard S, Pruvost J, Degrenne B, Legrand J. In press. Investigation of $\mathrm{H}_{2}$ production using the green microalga Chlamydomonas reinhardtii in a fully-controlled photobioreactor fitted with on-line gas analysis. Int J Hydrogen Energ.

Franco-Lara E, Havel J, Peterat F, Weuster-Botz D. 2006. Model-supported optimization of phototrophic growth. Biotechnol Bioeng 95:11771187.

Ghirardi ML, Togasaki RK, Seibert M. 1997. Oxygen-sensitivity of algal $\mathrm{H}_{2}$ production. Appl Biochem Biotech 63:141-151.

Ghirardi ML, Zhang L, Lee JW, Flynn T, Seibert M, Greenbaum E, Melis A. 2000. Microalgae: A green source of renewable $\mathrm{H}_{2}$. Trends Biotechnol 18:506-511.

Grossman A. 2000. Acclimation of Chlamydomonas reinhardtii to its nutrient environment. Protist 151:201-224.

Heifetz PB, Förster B, Osmond CB, Giles LJ, Boynton JE. 2000. Effects of acetate on facultative autotrophy in Chlamydomonas reinhardtii assessed by photosynthetic measurements and stable isotope analyses. Plant Physiol 122:1439-1445.

Janssen M, De Bresser L, Baijens B, Tramper J, Mur LR, Snel J, Wijffels RH. 2000. Scale-up aspects of photobioreactors: Effects of mixing-induced light/dark cycles. J Appl Phycol 12:225-237.

Kosourov S, Tsygankov AA, Seibert M, Ghirardi ML. 2002. Sustained hydrogen photoproduction by Chlamydomonas reinhardtii-Effects of culture parameters. Biotechnol Bioeng 78:731-740.

Kosourov S, Makarova V, Fedorov AS, Tsygankov A, Seibert M, Ghirardi ML. 2005. The effect of sulfur re-addition on $\mathrm{H}_{2}$ photoproduction by sulfur-deprived green algae. Photosynthesis Res 85:295-305.

Laurinavichene TV, Tolstygina IV, Galiulina RR, Ghirardi ML, Seibert M, Tsygankov AA. 2002. Dilution methods to deprive Chlamydomonas reinhardtii cultures of sulfur for subsequent hydrogen photoproduction. Int J Hydrogen Energ 27:1245-1249.

Laurinavichene TV, Fedorov AS, Ghirardi ML, Seibert M, Tsygankov AA. 2006. Demonstration of sustained hydrogen photoproduction by immobilized, sulfur-deprived Chlamydomonas reinhardtii cells. Int J Hydrogen Energ 31:659-667.

Melis A, Zhang L, Forestier M, Ghirardi ML, Seibert M. 2000. Sustained photobiological hydrogen gas upon reversible inactivation of oxygen evolution in the green alga Chlamydomonas reinhardtii. Plant Physiol 122:127-135.

Melis A. 2002. Green alga hydrogen production: progress, challenges, and prospects. Int J Hydrogen Energ 27(11-12):1217-1228.

Moser A. 1988. Bioprocess technology: Kinetics and reactors. New York: Springer. p. 451.

Muller-Feuga A. 1998. Growth as a function of rationing: A model applicable to fish and microalgae. J Exp Mar Biol Ecol 236:1-13.

Park W, Moon I. 2007. A discrete multi states model for the biological production of hydrogen by phototrophic microalga. Biochem Eng J 36:19-27.

Posewitz MC, Smolinski SL, Kanakagiri S, Melis A, Seibert M, Ghirardi ML. 2004. Hydrogen photoproduction is attenuated by disruption of an isoamylase gene in Chlamydomonas reinhardtii. Plant Cell 16:21512163.

Pottier L. 2005. Modélisation des photobioréacteurs pour la valorisation des microalgues. Thèse de doctorat, Université de Nantes.

Pottier L, Pruvost J, Deremetz J, Cornet J, Legrand J, Dussap C. 2005. A fully predictive model for one-dimensional light attenuation by Chlamydomonas reinhardtii in a torus photobioreactor. Biotechnol Bioeng 91:569-582.

Pruvost J, Pottier L, Legrand J. 2006. Numerical investigation of hydrodynamic and mixing conditions in a torus photobioreactor. Chem Eng Sc 61:4476-4489.

Tsygankov AA, Kosourov SN, Tolstygina IV, Ghirardi ML, Seibert M. 2006. Hydrogen production by sulfur-deprived Chlamydomonas reinhardtii under photoautotrophic conditions. Int J Hydrogen Energ 31:15741584 .

Wykoff DD, Davies JP, Melis A, Grossman AR. 1998. The regulation of photosynthetic electron transport during nutrient deprivation in Chlamydomonas reinhardtii. Plant Physiol 117:129-139. 